\title{
Influence of Proanthocyanidin on Motility and Osmotic Resistance Parameters of Merino Ram Sperm During Short Term Storage
}

\author{
Fatih AVDATEK $^{1 *}$, Deniz YENİ ${ }^{1}$, Umut TAŞDEMİR ${ }^{2}$ \\ ${ }^{1}$ Afyon Kocatepe University, Faculty of Veterinary Medicine, Department of Reproduction and Artificial Insemination, \\ 03200, Afyonkarahisar, Türkiye \\ ${ }^{2}$ Aksaray University, Faculty of Veterinary Medicine, Department of Reproduction and Artificial Insemination, \\ 68100, Aksaray, Türkiye
}

\begin{abstract}
The activity of proanthocyanidin oligomers is approximately 50 times greater than that of vitamin $\mathrm{C}$ and vitamin $\mathrm{E}$ in terms of antioxidant action. The aim of this study is to investigate the effects of different doses proanthocyanidin adding to extender on ram sperm motility, membran integrity and viability test, during liquid storage of ram semen. Ejaculates were collected from four Merino rams using an electroajaculator once a week and this process was repeated six times in non-breeding season. Ejaculates were split into four aliquots and diluted to a final concentration of $150 \times 10^{6} \mathrm{spermatozoa} / \mathrm{ml}$ with the base extender containing proanthocyanidin $\left(10,50\right.$ and $100 \mu \mathrm{g} / \mathrm{ml}$ ) and no additive (control). Diluted semen samples were transferred and stored at $+4^{\circ} \mathrm{C}$ and sperm motility, membrane integrity and viability was analysed in determined intervals during three days storage period. Motility was evaluated subjectively by a phase contrast microscopy at $37^{\circ} \mathrm{C}$. Membrane integrity and viability was analysed in hypo-osmotic resistance test with eosin staining test. After 24, 48 and $72 \mathrm{~h}, 10 \mu \mathrm{g} /$ $\mathrm{ml}$ proanthocyanidin treatment sperm samples presented higher motility and HOST/E test results than control group $(\mathrm{P}<0.05)$ in ram semen stored at $+4^{\circ} \mathrm{C}$. In conclusion, it was determined that the doses of $10 \mu \mathrm{g} / \mathrm{ml}$ of proanthocyanidin added to extender in $+4{ }^{\circ} \mathrm{C}$ storage of ram sperm showed a protective effect compared to the control group.
\end{abstract}

Key Words: Ram semen, Proanthocyanidin, Motility, Short term storage, Osmotic resistance

\section{$* * *$ \\ Kısa Süreli Saklanan Merinos Koç Spermasında Proantosiyanidin Motilite ve Ozmotik Direnç Parametreleri Üzerine Etkisi}

ÖZ

Proantosiyanidin oligomerlerinin aktivitesi, antioksidan etki açısından C vitamini ve $\mathrm{E}$ vitaminine göre yaklaşık 50 kat daha fazladır. Bu çalışmanın amacı, koç spermasının kısa süreli saklanmsı sırasında, farklı dozlardaki sulandırıcıya eklenen proantosiyanidin, koç spermatozoon motilitesi, membran bütünlüğü ve canlılı̆̆1 üzerine etkilerini araştırmaktır. Ejakülatlar, sezon dişında dört Merinos koçtan elektroajakülatör yardımıyla haftada bir kez toplandı ve bu işlem altı kez tekrarlandı. Ejakülatlar dört eşit parçaya bölünerek proantosiyanidin (10, 50 ve 100 ug / ml) içeren ve hiçbir katk1 maddesi içermeyen (kontrol) sulandırıcılar ile nihai ml'de 150x106/ml spermatozoa olacak şekilde sulandırıldı. Sulandırılan sperma örnekleri $+4{ }^{\circ} \mathrm{C}^{\prime}$ de 72 saat süresince saklandı ve spermatozoa motilitesi, membran bütünlüğü ve canlllığ1 üç günlük saklama süresi boyunca değerlendirildi. Motilite, $37^{\circ} \mathrm{C}^{\prime} \mathrm{de}$ faz kontrast mikroskop ile sübjektif olarak değerlendirildi. Membran bütünlüğü ve canlllğ̆1, eozin boyama testi ile hipoozmotik direnç testinde (HOST/E) değerlendirildi. 24, 48 ve 72 saat sonra, $+4{ }^{\circ}$ C'de saklanan koç spermasinda $10 \mu \mathrm{g} / \mathrm{ml}$ proantosiyanidin ile muamele edilmiş spermatozoon örnekleri kontrol grubuna göre daha yüksek motilite ve HOST / Eosin test sonuçları göstermiştir $(\mathrm{p}<0,05)$. Sonuç olarak koç sperminin $+4{ }^{\circ} \mathrm{C}^{\prime} \mathrm{de}$ saklanmasında sulandırıcıya eklenen $10 \mu \mathrm{g} / \mathrm{ml}$ proantosiyanidin kontrol ve diğer antioksidan gruplarına göre daha iyi bir koruyucu etki gösterdiği belirlendi.

Anahtar Kelimeler: Koç sperması, Proantosiyanidin, Motilite, Kısa Süreli Saklama, Ozmotik Direnç

To cite this article: Avdatek. F. Yeni D. Tassdemir U. Influence of Proanthocyanidin on Motility and Osmotic Resistance Parameters of Merino Ram Sperm During Short Term Storage. Kocatepe Vet J. (2020) 13(4): 362-367

Submission: 29.09.2020 Accepted: 04.11.2020 Published Online: 17.11.2020

ORCID ID; FA: 0000-0003-2345-8826, DY:0000-0002-9105-5677, UT: 0000-0003-2827-1286

*Corresponding author e-mail: favdatek@aku.edu.tr 


\section{GİRİş}

Spermanın k1sa süreli (likit saklama) saklanmas1 sperma 1sısının belirli seviyeye kadar düşürülmesi (0$5^{\circ} \mathrm{C}$ veya $\left.10-15^{\circ} \mathrm{C}\right)$ ve bu düzeylerde spermatozoanın geri dönüşümlü olarak inaktive edilmesi esasina dayanır. Bazı bilim insanları likit saklama için en uygun sicaklıkların $10-15^{\circ} \mathrm{C}$ olduğunu, diğer bir grup ise, koç ve boğa spermalarının canlılıklarını devam ettirebilmeleri için $0-5^{\circ} \mathrm{C}$ arasında değerlerin daha iyi saklama aralıkları olduğunu iddia etmişlerdir (Saloman ve Maxwell 2000, Johnson ve ark. 2000, Huo ve ark. 2002). Koçlarda sperma kalitesindeki düşüşün en önemli nedenlerinden biri oksidatif hasardir. Spermanın saklanması sirasinda serbest radikaller ve reaktif oksijen türleri (ROS) üretilir, ortaya çıkan ROS lipid peroksidasyona ve spermatozoonun normal fizyolojik fonksiyonunun bozulmasina yol açar (Aitken 2017). Koç spermasında çoklu doymamış yağ asitlerinin yoğunluğu diğer türlerdekinden daha fazladır, dolayısıyla koç spermatozoonu oksidatif hasara karşı duyarlıdır (Gündoğan ve ark. 2010). Yapılan çalışmalarda, sperma sulandırıcılarına antioksidanların eklenmesinin, serbest radikallerin ve ROS'un etkili bir şekilde atılmasına neden olduğu, böylece spermatozoonu oksidatif hasardan koruyarak spermatozoon kalitesini artırdı̆̆1 ve spermanın saklama süresini uzattı̆̆1 bildirilmektedir (Kasimanickam ve ark. 2011, Zakošek ve ark. 2017).

Oligomerik proantosiyanidin (OPC'ler) olarak da bilinen proantosiyanidinler, flavonoidler denen geniş ailenin bir parçasıdırlar ve bunlar üzüm çekirdeği ekstraktı ve çam kabuğu ekstraktında bulunmaktadır. OPC iki ila beş polimere sahiptir ve suda oldukça iyi çözünürler (Brillouet ve ark. 2017). OPC’ler güçlü antioksidanlardır. Etkili hidrojen bağı ve eşleşmemiş bir elektronun yer değiştirmesi, OPC'lere güçlü bir antioksidan özelliği sağlamaktadır (Han ve ark. 2016). $\mathrm{Bu}$ proantosiyanidinlerin serbest radikalleri inhibe ederek askorbik asit ve $E$ vitamininden daha etkin antioksidan özelliğe sahip olduğu (Nandakumar ve ark. 2008) ve serbest radikallerin neden olduğu hücre lipidleri, proteinler ve DNA hasarını engellediği belirtilmektedir (Bagchi ve ark. 1997). LDL seviyesini düşürüp birçok hastalığın gelişimini yavaşlattığ1, (Garavaglia ve ark. 2016) oligomerik bileşikleri, serbest radikallere ve oksidatif strese karşı geniş bir biyolojik, farmakolojik ve terapötik aktivite spektrumuna sahip olduğu söylenmektedir (Bagchi ve ark. 2000). Üzüm zar1, antosiyaninler ve flavonollar1 içerirken çekirdek ise; flavan-3-ol monomerleri ve gallik asit türevleri içerir. Flavan-3-ol basit monomerleri (kateşin ve izomeri epikateşin); oligomer ve polimer moleküllerini oluşturur (Nunes ve ark. 2016). Alkhedaide ve ark. (2016). OPC’lerin güçlü bir antioksidan olduklarını ve ratları kadminyum kaynaklı testis disfonksiyonlarına karşı etkili bir şekilde koruduğunu ortaya koymuşlardır. Day ve ark. (1997). üzüm özlerinin, $A, C$ ve $E$ vitaminleri gibi diğer antioksidanların etkinliğini artırdığını bildirdi. Serbest radikal temizleyici olarak kat kat daha güçlü oldukları için, bu vitaminleri diğer işlevlerini yerine getirmek üzere serbest bırakırlar. Koç spermasının likit olarak ya da dondurularak saklanmasinda sulandirıciya antioksidan özelliğinden yararlanmak amaciyla ilave edilen proantosiyanidin ile ilgili herhangi bir çalışmaya rastlanmamış olması sunulan çalışmanın özgünlügünü ortaya koymaktadir.

$\mathrm{Bu}$ çalışma farklı yoğunlukta sulandırıcısına katılan proantosiyanidinin koç spermasının kısa süreli saklanmasinda (0., 24., 48. ve 72 . saat) spermatozooa motilite ve ozmotik direnç parametreleri üzerine olan etkileri belirlemek amacıyla yapılmıştır.

\section{MATERYAL VE METOT}

Araştırmamızın materyalini A.K.Ü Hayvancılık Uygulama ve Araştırma Merkezi bünyesindeki 2-3 yaşlı 4 adet Merinos koçlar oluşturdu. Damızlık hayvanlar arasından, fenotipik olarak 1rk özelliklerini yansıtanlar çalışma için belirlendi. Seçilen koçlar androlojik açıdan muayene edildi. Genital organlara ait herhangi bir patolojik lezyon olmadığ1 kontrol edildi. Koçlar yarı açık besi şartlarında tane-kaba yem karışık olarak beslendi. Koçlardan aşım sezonu dışında haftada bir kez altı hafta boyunca sperma elektroejakülatör yardımıla alındı (Hafez 1987). Temel sulandırıcı Tris içine değişik yoğunluklarda proanthocyanidin $(10,50$ ve $100 \mu \mathrm{g} / \mathrm{ml})$ ve antioksidansız (kontrol) 4 grup oluşturuldu. Spermalar koçlardan alındıktan sonra bir tüpte birleştirilerek spermatolojik muayeneleri yapıldıktan sonra 4'e ayrild1. Sperma örnekleri önceden hazırlanmış sulandırıcı grupları ile ml'de 150x106 olacak şekilde sulandırıldı. Spermalar $5^{\circ} \mathrm{C}^{\prime}$ de $2-2,5$ saat ekilibrasyondan sonra $5{ }^{\circ} \mathrm{C}$ 'de 0 . saat motilite ve membran bütünlüğü değerlendirmeleri yapıldıktan sonra $5^{\circ} \mathrm{C}$ 'de muhafaza edilip 24., 48. ve 72 . saat motilite ve membran bütünlüğü değerlendirmeleri yapılıp kaydedildi. Çalışma süresi boyunca bu işlem 6 kere yapild1.

\section{Spermatolojik Muayeneler}

Motilite muayeneleri sıcaklı̆̆1 ayarlanmış 1sıtma tablalı faz kontrast mikroskop yardimiyla subjektif olarak değerlendirildi (Demirci 2002).

Hipo-ozmotik şişme testinin Eosin ile birlikte uygulandığ1 $\mathrm{HOS} / \mathrm{E}$ test, $37^{\circ} \mathrm{C}$ 'taki $100 \mathrm{mOsm}$ 'luk HOST solüsyonundan $1 \mathrm{ml}$ alınıp üzerine sperma numunesinden $10 \mu \mathrm{l}$ eklenerek eosin boyasi ilave edilip karışım $37^{\circ} \mathrm{C}$ 'lik su banyosunda $30 \mathrm{dk}$. inkübasyona birakılması şeklinde yapıldı. Spermatozoon baş kısmının tamamın ya da bir bölümünün boya alıp almamasına ve kuyruktaki çeşitli şekillerdeki kıvrilma veya şişmeye olup olmamasına göre değerlendirildi. 
I. Kuyruk şişmiş, baş boya almamış HOS+/E-

II. Kuyruk şişmemiş, baş boya almamış HOS-/E-

III. Kuyruk şişmiş, baş boya almış HOS +/E+

IV. Kuyruk şişmemiş, baş boya almış HOS-/E+ (Gündoğan ve ark. 2010)

\section{İstatistiksel Analiz}

Shapiro-Wilk testi sonucu verilerin normal olarak dağıldı görüldü ve elde ettiğimiz bulguların istatistiksel analizinde tek yönlü varyans analizi (ANOVA) ile yapild1. Post-hoc Duncan testi gruplar arası farkin önemini belirlemek için uyguland. Analizler SPSS (13.0) paket programında gerçekleştirildi.

\section{BULGULAR}

\section{Saat Spermatozoon Motilite ve Membran Bütünlüğü Değerleri}

0 . saatte motilite ve HOS/E test değerleri Tablo 1' de sunuldu. Motilite oranlarında gruplar arasinda istatistiksel olarak bir fark olmadığ1 gözlemlenmiş, $\mathrm{H}+\mathrm{E}$ - oranlarında ise $10 \mu \mathrm{g} / \mathrm{ml}$ ve $100 \mu \mathrm{g} / \mathrm{ml}$ gruplardaki artış kontrol grubuna göre istatistiki olarak önemli bulunmuştur $(\mathrm{p}<0,05)$.

\section{Saat Spermatozoon Motilite ve Membran Bütünlüğü Değerleri}

Motilite oranlarında gruplar arasında istatistiksel olarak bir fark olmadı̆̆1 gözlemlenmiş (Tablo 2), $\mathrm{H}+\mathrm{E}$ - oranlarinda ise $10 \mu \mathrm{g} / \mathrm{ml}$ ve $100 \mu \mathrm{g} / \mathrm{ml}$ gruplardaki artış kontrol grubuna göre istatistiki olarak önemli bulunmuştur $(\mathrm{p}<0,05)$.

\section{Saat Spermatozoon Motilite ve Membran Bütünlüğü Değerleri}

Motilite ve HOS/E test oranlar1 Tablo 3' de sunuldu. Motilite oranlarında $10 \mu \mathrm{g} / \mathrm{ml}$ 'lik gruptaki artış kontrol ve diğer gruplara göre istatistiki açıdan önemli bulundu $(\mathrm{p}<0,05)$. H+E- oranları açısından kontrole göre tüm antioksidan içeren gruplardaki artış istatistiki açıdan önemli bulundu $(\mathrm{p}<0,05)$.

\section{Saat Spermatozoon Motilite ve Membran Bütünlüğü Değerleri}

Tablo 4' de motilite ve HOS/E test oranlar1 verilmiștir. Motilite oranlarında $10 \mu \mathrm{g} / \mathrm{ml}$ lik gruptaki artış kontrol ve diğer gruplara göre istatistiki açıdan önemli bulundu $(\mathrm{p}<0,05)$. H+E- oranları aç1sından kontrole göre $10 \mu \mathrm{g} / \mathrm{ml}$ ve $50 \mu \mathrm{g} / \mathrm{ml}$ gruplardaki artış istatistiki açıdan önemli bulundu $(\mathrm{p}<0,05)$.

Tablo 1. Çalışmada 0. saatte elde edilen ortalama motilite ve HE test oranları ( $\bar{X} \pm$ SEM, n:G).

Table 1. Mean motility and HE test obtained at $0 . \mathrm{h}$ in the study ( $\overline{\mathrm{X}} \pm \mathrm{SEM}, \mathrm{n}: 6)$.

\begin{tabular}{llllll}
\hline Gruplar & $\begin{array}{l}\text { Motilite } \\
\mathbf{( \% )}\end{array}$ & $\begin{array}{l}\mathbf{H}+/ \mathbf{E}- \\
\mathbf{( \% )}\end{array}$ & $\begin{array}{l}\mathbf{H}-/ \mathbf{E}- \\
\mathbf{( \% )}\end{array}$ & $\begin{array}{l}\mathbf{H}+/ \mathbf{E}+ \\
\mathbf{( \% )}\end{array}$ & $\begin{array}{l}\mathbf{H}-/ \mathbf{E}+ \\
\mathbf{( \% )}\end{array}$ \\
\hline $\mathbf{K o n t r o l}$ & $83,3 \pm 2,10$ & $68,2 \pm 0,80^{\mathrm{b}}$ & $10,5 \pm 0,56^{\mathrm{ab}}$ & $11,8 \pm 0,79^{\mathrm{a}}$ & $9,1 \pm 0,70^{\mathrm{b}}$ \\
$\mathbf{1 0} \boldsymbol{\mu g} / \mathbf{m l}$ & $86,6 \pm 2,10$ & $73,5 \pm 0,76^{\mathrm{a}}$ & $10,0 \pm 0,36^{\mathrm{b}}$ & $10,0 \pm 0,85^{\mathrm{ab}}$ & $6,5 \pm 0,42^{\mathrm{c}}$ \\
$\mathbf{5 0} \boldsymbol{\mu g} / \mathbf{m l}$ & $83,3 \pm 2,58$ & $67,3 \pm 0,66^{\mathrm{b}}$ & $12,8 \pm 1,35^{\mathrm{a}}$ & $8,3 \pm 0,84^{\mathrm{b}}$ & $11,5 \pm 0,61^{\mathrm{a}}$ \\
$\mathbf{1 0 0} \mathbf{\mu g} / \mathbf{m l}$ & $81,6 \pm 1,66$ & $72,5 \pm 1,66^{\mathrm{a}}$ & $10,3 \pm 0,55^{\mathrm{b}}$ & $8,3 \pm 0,49^{\mathrm{b}}$ & $8,8 \pm 1,07^{\mathrm{b}}$ \\
\hline
\end{tabular}

a-b: Her bir sütun içerisinde farklı harf taşıyan değerler arasındaki farklar istatistiki açıdan önemlidir $(\mathrm{P}<0.05)$

Tablo 2. Çalışmada 24. saatte elde edilen ortalama motilite ve HE test oranları ( $\bar{X} \pm$ SEM, n:6).

Table 2. Mean motility and HE test obtained at 24. $\mathrm{h}$ in the study ( $\overline{\mathrm{X}} \pm$ SEM, n:6).

\begin{tabular}{llllll}
\hline Gruplar & $\begin{array}{l}\text { Motilite } \\
(\mathbf{\%})\end{array}$ & $\begin{array}{l}\mathbf{H}+/ \mathbf{E}- \\
\mathbf{( \% )}\end{array}$ & $\begin{array}{l}\mathbf{H}-/ \mathbf{E}- \\
\mathbf{( \% )}\end{array}$ & $\begin{array}{l}\mathbf{H}+/ \mathbf{E}+ \\
\mathbf{( \% )}\end{array}$ & $\begin{array}{l}\mathbf{H}-/ \mathbf{E}+ \\
\mathbf{( \% )}\end{array}$ \\
\hline $\mathbf{K o n t r o l}$ & $75,0 \pm 2,23^{\mathrm{ab}}$ & $62,0 \pm 1,52^{\mathrm{c}}$ & $16,0 \pm 0,96^{\mathrm{b}}$ & $11,6 \pm 1,33^{\mathrm{a}}$ & $10,3 \pm 1,56$ \\
$\mathbf{1 0} \boldsymbol{\mu g} / \mathbf{m l}$ & $78,3 \pm 1,66^{\mathrm{a}}$ & $67,8 \pm 0,47^{\mathrm{ab}}$ & $11,8 \pm 0,79^{\mathrm{c}}$ & $11,1 \pm 1,07^{\mathrm{a}}$ & $9,1 \pm 0,94$ \\
$\mathbf{5 0} \mathbf{~} \mathbf{g} / \mathbf{m l}$ & $73,3 \pm 2,10^{\mathrm{ab}}$ & $64,8 \pm 0,79^{\mathrm{bc}}$ & $19,5 \pm 0,42^{\mathrm{a}}$ & $7,3 \pm 0,55^{\mathrm{b}}$ & $8,3 \pm 0,84$ \\
$\mathbf{1 0 0} \mathbf{\mu g} / \mathbf{m l}$ & $71,6 \pm 1,67^{\mathrm{b}}$ & $68,8 \pm 1,60^{\mathrm{a}}$ & $14,0 \pm 0,44^{\mathrm{b}}$ & $7,0 \pm 1,00^{\mathrm{b}}$ & $10,1 \pm 1,22$ \\
\hline
\end{tabular}

a-c: Her bir sütun içerisinde farklı harf taşıyan değerler arasındaki farklar istatistiki açıdan önemlidir $(\mathrm{P}<0.05)$ 
Tablo 3. Çalışmada 48. saatte elde edilen ortalama motilite ve HE test oranları ( $\bar{X}_{ \pm}$SEM, n:6).

Table 3. Mean motility and HE test obtained at $48 . h$ in the study ( $\bar{X}_{ \pm}$SEM, n:6).

\begin{tabular}{llllll}
\hline Gruplar & $\begin{array}{l}\text { Motilite } \\
(\%)\end{array}$ & $\begin{array}{l}\mathbf{H}+/ \mathbf{E}- \\
(\%)\end{array}$ & $\begin{array}{l}\mathbf{H}-/ \mathbf{E}- \\
\mathbf{( \% )}\end{array}$ & $\begin{array}{l}\mathbf{H}+/ \mathbf{E}+ \\
\mathbf{( \% )}\end{array}$ & $\begin{array}{l}\mathbf{H}-/ \mathbf{E}+ \\
\mathbf{( \% )}\end{array}$ \\
\hline $\mathbf{K o n t r o l}$ & $65,0 \pm 2,23^{\mathrm{b}}$ & $55,6 \pm 0,66^{\mathrm{b}}$ & $15,3 \pm 1,11^{\mathrm{b}}$ & $16,5 \pm 1,17^{\mathrm{a}}$ & $12,5 \pm 1,23^{\mathrm{a}}$ \\
$\mathbf{1 0} \boldsymbol{\mu g} / \mathbf{m l}$ & $76,6 \pm 2,10^{\mathrm{a}}$ & $63,0 \pm 0,96^{\mathrm{a}}$ & $20,6 \pm 0,55^{\mathrm{a}}$ & $7,5 \pm 0,76^{\mathrm{b}}$ & $9,3 \pm 0,80^{\mathrm{b}}$ \\
$\mathbf{5 0} \mathbf{\mu g} / \mathbf{m l}$ & $66,6 \pm 2,11^{\mathrm{b}}$ & $61,3 \pm 1,02^{\mathrm{a}}$ & $19,3 \pm 1,11^{\mathrm{a}}$ & $9,6 \pm 0,42^{\mathrm{b}}$ & $9,6 \pm 0,21^{\mathrm{b}}$ \\
$\mathbf{1 0 0} \boldsymbol{\mu g} / \mathbf{m l}$ & $63,3 \pm 2,10^{\mathrm{b}}$ & $60,5 \pm 0,76^{\mathrm{a}}$ & $16,1 \pm 0,94^{\mathrm{b}}$ & $9,8 \pm 0,79^{\mathrm{b}}$ & $13,5 \pm 1,08^{\mathrm{a}}$ \\
\hline
\end{tabular}

a-b: Her bir sütun içerisinde farklı harf taşıyan değerler arasındaki farklar istatistiki açıdan önemlidir $(\mathrm{P}<0.05)$

Tablo 4. Çalışmada 72. saatte elde edilen ortalama motilite ve HE test oranları ( $\bar{X} \pm S E M, n: 6)$.

Table 4. Mean motility and HE test obtained at 72 . h in the study ( $\bar{X}_{ \pm}$SEM, n:6).

\begin{tabular}{llllll}
\hline Gruplar & $\begin{array}{l}\text { Motilite } \\
(\%)\end{array}$ & $\begin{array}{l}\mathbf{H + / E}- \\
\mathbf{( \% )}\end{array}$ & $\begin{array}{l}\mathbf{H}-/ \mathbf{E}- \\
\mathbf{( \% )}\end{array}$ & $\begin{array}{l}\mathbf{H}+/ \mathbf{E}+ \\
\mathbf{( \% )}\end{array}$ & $\begin{array}{l}\mathbf{H}-/ \mathbf{E}+ \\
\mathbf{( \% )}\end{array}$ \\
\hline $\mathbf{K o n t r o l}$ & $55,0 \pm 2,23^{\mathrm{b}}$ & $53,5 \pm 0,76^{\mathrm{c}}$ & $19,1 \pm 0,70^{\mathrm{ab}}$ & $13,5 \pm 0,22^{\mathrm{a}}$ & $14,1 \pm 1,01^{\mathrm{a}}$ \\
$\mathbf{1 0} \boldsymbol{\mu g} / \mathbf{m l}$ & $68,3 \pm 1,66^{\mathrm{a}}$ & $59,8 \pm 0,70^{\mathrm{a}}$ & $21,5 \pm 0,76^{\mathrm{a}}$ & $8,3 \pm 1,11^{\mathrm{b}}$ & $10,3 \pm 0,98^{\mathrm{b}}$ \\
$\mathbf{5 0} \boldsymbol{\mu g} / \mathbf{m l}$ & $58,3 \pm 3,07^{\mathrm{b}}$ & $57,3 \pm 1,62^{\mathrm{ab}}$ & $21,4 \pm 0,56^{\mathrm{a}}$ & $8,5 \pm 0,56^{\mathrm{b}}$ & $11,0 \pm 1,23^{\mathrm{ab}}$ \\
$\mathbf{1 0 0} \boldsymbol{\mu g} / \mathbf{m l}$ & $55,0 \pm 2,23^{\mathrm{b}}$ & $55,5 \pm 0,76^{\mathrm{bc}}$ & $18,0 \pm 1,31^{\mathrm{b}}$ & $12,0 \pm 1,57^{\mathrm{a}}$ & $14,5 \pm 1,33^{\mathrm{a}}$ \\
\hline
\end{tabular}

a-c: Her bir sütun içerisinde farklı harf taşıyan değerler arasındaki farklar istatistiki açıdan önemlidir $(\mathrm{P}<0.05)$

\section{TARTIŞMA}

$\mathrm{Bu}$ çalışmada, sperma saklama süresi arttıkça, koç spermasının kalitesi azalma eğiliminde olmuştur. Bu azalma, spermatozoa oksidatif hasarıyla açılanabilir. Diğer türlere oranla koç spermatozoasının, düşük kolesterol-fosfolipid membranına oranına sahip olmas1 spermatozoay1 oksidatif hasara daha duyarlı hale getirmektedir (Gündoğan ve ark. 2010). Spermanın kısa süreli saklanmasında en önemli sperma kalite kriterlerinden biri de spermatozoon motilitesidir. Oksidatif stres ise spermatozoon motilitesinin değerlendirilmesindeki en önemli belirleyicidir. Koç sperma sulandırıcısına antioksidan ilave etmek spermatozoonlarin oksidayona maruz kalmasını önemli ölçüde engellerken aynı zamanda da spermanin saklanmasi sirasinda spermatozoonlarin motilitesinin artmasina yardımc olmaktadır. $\mathrm{Bu}$ çalışmada, OPC'nin eklenmesi, diğer antioksidanların değerlendirildiği önceki çalışmaların sonuçlarına benzer spermatozoon motilitesini etkili bir șekilde arttırmıștır (Bucak ve Tekin 2006, Tuncer ve ark. 2010, Avdatek ve Gündoğan M. 2018, Güngör ve ark., 2019). Membran bütünlüğü spermatozoon metabolizmasinın yanı sira kapasitasyon, akrozom reaksiyonu olayının oluşmasında gerekli olan bir unsurdur. Ozmotik toleransin ve ölü-canlı spermatozoon oranının birlikte ele alındığı HOS/E test, fertilitenin belirlenmesinde kullanılan önemli sperma kalite testlerinden biri olarak değerlendirilmektedir (Avdatek ve ark. 2018).
Çalışmamızda sulandırıcıya OPC'nin eklenmesi, diğer antioksidanların değerlendirildiği önceki çalışmaların sonuçlarına uygun olarak spermatozoon membran bütünlüğunü önemli bir şekilde koruduğunu gözlemledik. Saklama sürecinin uzaması spermada serbest radikaller ve ROS'un artışına bu artışın da eşik değeri aşması sonucu oksidatif strese neden olduğu, bu durumunda spermatozoa plazma membraninın yapısındaki doymamış yağ asitlerinin peroksidasyonuna neden olduğu bilinmektedir.

Çalışmamızın 0., 24., 48. ve 72. saat bulgularına bakıldığında farklı konsantrasyonlar değişik zaman dilimlerinde motilite ve membran bütünlüğ̈̈ üzerine olumlu etki yaptı ancak özellikle $10 \mu \mathrm{g} / \mathrm{ml}$ proantosiyanidin ilave edilen grup hem motilite hem de membran bütünlüğü yönünden değerlendirildiğinde kontrol ve diğer gruplara göre spermanın kısa süreli saklanmasında etkili olduğu belirlendi.

Sunulan çalışmamızı destekler nitelikte, Wen ve ark. (2019). teke spermasının kısa süreli saklanmasında sulandirıciya farklı dozlarda $(10,30,50$ ve $70 \mathrm{mg} / \mathrm{L})$ üzüm çekirdeği ekstresi proantosiyanidin ilave ederek 120 saate kadar spermatolojik parametreler ve diğer antioksidan parametreleri değerlendirdikleri çalışmalarında $30 \mathrm{mg} / \mathrm{L}$ ilave edilen grubun gerek kontrol gerekse diğer gruplara göre spermatozoon motilitesini, akrozom ve membran bütünlüğü artırdığını bildirmektedirler. Li ve ark. (2018) Guanzhong-Black domuz sperma sulandiricisina farklı konsantrasyonlarda oligomerik proantosiyanidin ilave ettikleri kısa süreli saklama çalısmalarında 50 
$\mu \mathrm{g} / \mathrm{mL}$ ilave edilen proantosiyanidinin spermatozoon motilitesi ve membran bütünlüğünü daha iyi koruduğunu bildirmektedirler.

Sperma sulandirıcisina proantosiyanidin ilave edilmesi sonucu spermatozoon motilitesinde ve membran bütünlüğündeki artışı en önemli nedeni proantosiyanidinlerin çok zengin antioksidan içeriğinden kaynaklandığı, üzümden elde edilen proantosiyanidin gibi flavonoidler zararlı serbest radikalleri oldukça etkili bir şekilde temizlediği, bu bileșiklerin hücre zarlarına gömülü olan yağlar ve LDL kaynaklı lipid peroksidasyon hasarının azaltmasında yararlı olduğu vurgulanmaktadır (Evans ve ark. 1996, Puiggròs ve ark. 2005). Bagchi ve ark. (1997) proantosiyadimlerin vücuda saniyeler içinde ve çok hızlı bir şekilde nüfuz ettiğini serbest radikal temizleyici olarak çok daha güçlü olduklarını böylece $A, C$ ve $E$ vitaminleri gibi diğer antioksidanların etkinliğini arttırarak bu vitaminlerin diğer işlevlerini yerine getirmeleri için onları serbest bıraktığını da bildirmektedir.

Çalışmamızla aynı yönde farklı türlerde yapılan çalışmalarda, Al-Daraji (2012) kısa süreli saklamak için horoz sperma sulandırıcılarına ilave ettiği farklı üzüm bileşenleri içeren çalışmasında proantosiyanidin ilavesinin spermatozoon motilitesini artırdığını bildirmektedir. Zhao ve ark. (2014) ratlarda intraperitonal olarak verdikleri cisplatin (DDP) ile indüklenmiş toksisitede gavaj yoluyla koruyucu madde olarak 200 ve $400 \mathrm{mg}$ proantosiyanidin uyguladikları çalışmalarında özellikle $400 \mathrm{mg}$ proantosiyanidin verilen gurubun cisplatin kaynaklı testis toksisitesini azalttığ ayrıca azalan spermatozoon motilitesini ve yoğunluğunu artırdığı bununla beraber artan anormal spermatazoon sayısını da azalttığını bildirmektedirler. Long ve ark. (2017). erkek farelere 10 gün boyunca günlük 75 ile $150 \mathrm{mg} / \mathrm{kg}$ arasında değişen miktarlarda mide içi proantosiyanidin verildikten sonraki 11. günde $\quad 40 \mathrm{mg} / \mathrm{kg}$ Zearalenone verdikleri çalışmalarında proantosiyanidinin spermatozoon kalitesini artırdığını ve testiste Zearalenone sebep olduğu toksisiteyi azalttığını bildirmektedirler. Su ve ark. (2011). üzüm çekirdeği proantosiyanidinin ekstresi'nin Nikel kaynaklı apoptoz ve oksidatif stresi dengeleyerek ratlarda spermatozoon motilitesini artırdığını belirtmektedir. Attia ve ark. (2010) farelerde yaptıkları çalışmalarında proantosiyanidinlerin doksorubisin ile indüklenen mutagenezin azaltılmasında ve en azından kısmen radikal süpürücü aktivitelerinde bulunan farelerin germinal hücrelerinde hücre proliferasyon değişikliklerinin azaltılmasında koruyucu bir role sahip olduğunu bildirmektedirler. Farklı türlerde farklı uygulama yöntemlerine göre alınan sonuçların elde edilen bulgularımızla uyumlu olmas1 proantosiyanidinin seçkin antioksidan özelliğini değişik ortamlarda dahi gösterebildiği yönünde yorumlanmıştır.

\section{SONUÇ}

Araştırmamızda sperma sulandırıcısına ilave ettiğimiz farklı yoğunluktaki proantosiyanidinin $10 \mu \mathrm{g} / \mathrm{ml}$ dozunda spermatozoon motilitesi ve membran bütünlüğü üzerine iyileştirici etkisi olduğu düşünülmektedir.

\section{TEŞEKKÜR}

Bu çalışma 'International Conference on Agriculture, Forest, Food, Veterinary Science and Technologies' kongresinde sözlü sunum olarak sunulmuştur.

Çı1kar Çatışması: Yazarlar, çıkar çatışması olmadığını beyan eder.

\section{KAYNAKLAR}

Aitken R.J. Reactive oxygen species as mediators of sperm capacitation and pathological damage. Mol. Reprod. Dev., 2017, 84: 1039-1052.

Al-Daraji H. The Use of Certain Grape Constituents for Improve Semen Quality and Storage Ability of Diluted Roosters' Semen. Am. J. PharmTech Res., 2012, 2(5): 308-322.

Attia S.M., Bakheet A.S., Al-Rasheed N.M. Proanthocyanidins produce significant attenuation of doxorubicin-induced mutagenicity via suppression of oxidative stress. Oxidative Medicine and Cellular Longevity, 2010, 3(6): 404-413.

Avdatek F., Gündoğan M. Effects of Some Antioxidant Additives on Spermatological Parameters, Oxidative Stress and DNA Damage After Freezing-Thawing Process in Ram Semen. F.U. Vet. J. Health Sci., 2018, 32 (2): 135-142.

Avdatek F., Yeni D., Gündoğan M. Merinos Koçlarda Spermaya Katılan Antioksidanların Kısa süreli Saklama Sirasinda Spermatolojik Parametreler ve DNA Hasarı Üzerine Etkileri. Kocatepe Vet J., 2018, 11(2): 126-133.

Bagchi D., Bagchi M., Stohs S.J., Das D.K., Ray S.D., Kuszynski C.A., Joshi S.S., Pruess H.G. Free radicals and grape seed proanthocyanidin extract: importance in human health and disease prevention. Toxicol, 2000, 148: 187-197.

Bagchi D., Garg A., Krohn R.L., Bagchi M., Tran M.X., Stohs S.J. Oxygen free radical scavenging abilities of vitamins $\mathrm{C}$ and $\mathrm{E}$, and a grape seed proanthocyanidin extract in vitro. Research Communications in Molecular Pathology and Pharmacology, 1997, 95(2): 179-189.

Brillouet J., Fulcrand H., Carrillo S., Roumeas L., Romieu C. Isolation of native proanthocyanidins from grapevine (Vitis vinifera) and other fruits in aqueous buffer. J. Agric. Food Chem., 2017, 65: 2895-2901.

Bucak M.N., Tekin N. Protective effect of taurine, glutathione and trehalose on the liquid storage of ram semen. Small Ruminant Res, 2006, 73: 103-108.

Day A.P., Kemp H.J., Bolton C., Hartog M., Stansbie D. Effect of concentrated red grape juice consumption on 
serum antioxidant capacity and low - density lipoprotein oxidation. Ann Nutr Metab, 1997, 41: 353-357.

Demirci E. Evcil hayvanlarda reprodüksiyon, Suni tohumlama ve androloji ders notları (1nd ed). F.Ü.Vet.Fak., 2002, Ders Teksiri No:53 Elazı̆g.

Evans R., Miller N.J., Paganga G. Structure -antioxidant activity relationships of flavonoids and phenolic acids. Free Radic Bio Med, 1996, 20: 933-956.

Garavaglia J., Markoski M.J., Oliveira A., Marcadenti A. Grape Seed Oil Compounds: Biological and Chemical Actions for Health. Nutrition and Metabolic Insights, 2016, 9: 59-64.

Gundogan M., Yeni D., Avdatek F., Fidan A.F. Influence of sperm concentration on the motility, morphology, membrane and DNA integrity along with oxidative stress parameters of ram sperm during liquid storage. Anim Reprod Sci., 2010, 122: 200-207.

Güngör, Ş., İnanç M.E., Ata A. Effect of gallic acid on ram semen spermatological parameters at $+4{ }^{\circ} \mathrm{C}$ storage. Eurasian Journal of Veterinary Sciences 2019, 35 (2), 8792.

Hafez, E.S.E. Semen Evaluation (5 Ed) In: Hafez, E. S. E. (Ed) Reproduction in farm animals. Philadelphia. Lea and Fabiger. 1987.

Han M., Song P., Chang H., Rezaei A., Farrar S., Brown, M.A., Xi, M. Dietary grape seed proanthocyanidins (GSPs) improve weaned intestinal microbiota and mucosal barrier using a piglet model. Oncotarget, 2016, 7 : 80313-80236.

Huo L.J., Yue K.Z., Yang Z.M. Characterization of viability, mitochondrial activity, acrosomal integrity and capacitation status in boar sperm during in vitro storage at different ambient temperatures. Reprod Fert Develop., 2002, 14: 509-514.

Johnson L.A., Weitze K.F., Fiser P., Maxwell W.M.V. Storage of boar semen. Anim Reprod Sci., 2000; 62: 143-172.

Kasimanickam R., Kasimanickam V., Tibary A., Pelzer K. Effect of semen 344 extenders on sperm parameters of ram semen during liquid storage at $4^{\circ} \mathrm{C} .345$ Small Ruminant Res, 2011, 99: 208-213.

Li Q., Shaoyong W., Li Y., Chen M., Hu Y., Liu B., Yang G., Hu J. Effects of oligomeric proanthocyanidins on quality of boar semen during liquid preservation at $17{ }^{\circ} \mathrm{C}$. Animal Reproduction Science, 2018, 98: 47-56.

Long M., Yang S., Zhang Y., Li P., Han J., Dong S., Chen $\mathbf{X}$., He J. Proanthocyanidin protects against acute zearalenone-induced testicular oxidative damage in male mice. Environ Sci Pollut Res., 2017, 24: 938-946.

Nandakumar V., Singh T., Katiyar S.K. Multi-targeted prevention and therapy of cancer by proanthocyanidins. Cancer Letters, 2008, 269.

Nunes M.A., Pimentel F., Costa A.S.G., Alvers R.C., Oliveria M.B.P.P. Cardioprotective properties of grape seed proanthocyanidins: An update. Trends in Food Science \& Technology, 2016, 57: 31-39.

Puiggròs F., Llópiz N., Ardévol A., Bladé C., Arola L., Salvadó M.J. Grape seed procyanidins prevent oxidative injury by modulating the expression of antioxidant enzyme systems. J. Agric. Food Chem., 2005, 53: 60806086.

Saloman S., Maxwell W.M.C. Storage of ram semen. Anim. Reprod. Sci., 2000; 62 (1-3): 77-111.

Su L., Deng Y., Zhang Y., Li C., Zhang R., Sun Y. Protective e_ects of grape seed procyanidin extract against nickel sulfate-induced apoptosis and oxidative stress in rat testes. Toxicol. Mech. Methods, 2011, 21: 487-494.

Tuncer P.B., Bucak M.N., Büyükleblebici S., Sarı̈zkan S., Yeni D., Eken A., Akalın P.P., Kinet H., Avdatek F., Fida A.F., Gündoğan M. The effect of cysteine and glutathione on sperm and oxidative stress parameters of post-thawed bull semen. Cryobiol, 2010, 61: 303-307.

Wen F., Li Y., Feng T., Du Y., Ren F., Zhang L., Han N., Ma S., Li F., Wang P., Hu J. Grape Seed Procyanidin Extract (GSPE) Improves Goat Sperm Quality When Preserved at $4{ }^{\circ} \mathrm{C}$. Animals, 2019, 9: 810; doi:10.3390/ani9100810

Zakošek P.M., Mrkun J., Nemec S.A., Zrimšek P. Improvement of liquid stored boar semen quality by removing low molecular weight proteins and supplementation with $\alpha$-tocopherol. Anim. Reprod. Sci., 2017, 186: 52-61.

Zhao Y., Gao L., Zhang H., Guo J., Guo P. Grape seed proanthocyanidin extract prevents DDP-induced testicular toxicity in rats. Food Funct., 2014, 5: 605-611. 